\title{
Language Errors in an English-Medium Instruction University Setting: How do Language versus Content Teachers Tackle them?
}

\author{
DAVID LASAGABASTER
}

Aintzane DoIz

University of the Basque Country UPV/EHU

Received: 5 March 2018 / Accepted: 30 April 2018

ISSN: $1697-7467$

\begin{abstract}
Since attention to content usually prevails over language matters in Englishmedium classes at university level, there are relatively few studies dealing with the content teachers' position on language issues. This is why the present study intends to (i) compare the content and language teacher's position regarding errors in students' written work; (ii) identify the most frequent errors in the students' essays; and (iii) determine whether there is a correlation between the mark assigned by the content teacher and the number/ type of errors the language teacher comes across. In order to address these issues, we analysed 20 essays produced by students who were taking "World economic history" at the University of the Basque Country and compared the corrections made by the content and the language teachers. The results confirmed that the content teacher's and the language teachers' position with respect to language differs significantly, that grammar errors are the most frequent errors, and that there is no correlation between the number of errors and mark awarded for the essays. We believe that comparing language and content teachers' approaches to error correction may shed light on how we can improve students' writing skills.
\end{abstract}

Keywords: content teacher; language teacher, classes in English, error correction; writing skills

Los errores lingüísticos en un contexto universitario de enseñanza en inglés: ¿cómo los afronta el profesorado de lengua versus el de contenido?

RESUMEN: En las clases en inglés del ámbito universitario el contenido prima claramente sobre la lengua, lo que ha podido motivar que sean relativamente escasos los estudios sobre la atención que presta el profesorado de contenido a la cuestión lingüística. Ante este vacío este estudio pretende (i) comparar la actitud del profesorado de contenido y de lengua ante los errores cometidos en trabajos escritos; (ii) identificar los tipos de errores de lengua más frecuentes en dichos trabajos y (iii) determinar si existe una correlación entre la nota dada por el profesor de contenido y el número/tipo de errores de las composiciones. Para dar respuesta a las cuestiones planteadas se analizaron 20 composiciones de alumnos del curso de "World economic history" de la Universidad del País Vasco y se compararon las correcciones del profesorado de contenido y el de lengua. Los resultados confirmaron que la postura con 
respecto a la lengua del profesorado de contenido y de lengua difiere de manera significativa, que los errores más comunes son los de gramática y que no existe una correlación entre el número de errores y la nota de los trabajos escritos. Este trabajo contribuirá a la mejora de la competencia escrita de los alumnos.

Palabras clave: profesorado de contenido; profesorado de lengua; clases de contenido en inglés; corrección de errores, competencia escrita

\section{INTRODUCTION}

Applied linguists (Lyster, 2007; Nikula, Dafouz, Moore \& Smit, 2016; Valcke \& Wilkinson, 2017) recurrently underline the need to integrate language and content in contexts where students are taught in a foreign language. However, attention to language in courses in English is much more common in secondary education than at tertiary level. Thus, studies have revealed that attention to language forms is overtly neglected, both when university lecturers have been canvassed (Aguilar, 2017) and observed in their classes (Airey, 2012; Costa, 2012).

The vast majority of EMI (English-medium instruction) lecturers in the European context are non-native speakers of English (Costa, 2012; Lasagabaster, in press) who are willing to teach content but not language. In fact, one of the most frequent statements made by EMI lecturers is that they are not language teachers and, therefore, language teaching is not regarded as part of their job, as confirmed by studies carried out in contexts as diverse as Sweden (Airey, 2012), Italy (Costa, 2012) or Spain (Dafouz, 2011). This neglect of the linguistic aspect on EMI programmes may adversely affect students' learning outcomes.

However, it is striking that the effects of EMI on content have been largely overlooked, as proven by the fact that the studies on this issue are scant (e.g. Costa \& Mariotti, 2017; Dafouz, Camacho \& Urquia, 2014; Hernández-Nanclares \& Jiménez-Muñoz, 2017). Macaro (2018) points out that this is a reflection of the insufficient financial support for the introduction of EMI in most university contexts. What is more, the analysis of the interaction between language competence and content learning is even more conspicuous by its absence. Collaboration between language and content teachers is necessary to make content teachers more aware of the importance of language in content learning (Lasagabaster, 2018). As Symon and Weinberg (2015) point out, merely implementing EMI is unlikely to increase language learning if there is no appropriate linguistic support framework.

In this paper we look at the issue of assessment from a new angle. We have concentrated on one particular language skill, namely EMI students' writing, from both the content teacher's and the language teacher's perspective. In order to achieve this objective, we will analyse whether language-related errors are similarly identified by language versus content teachers and whether language errors and content marks interact. We believe that comparing language and content teachers' approaches to error correction may provide clues as to how we can improve students' writing skill by combining the best of both worlds. 


\section{LANGUAGE ERRORS AND FEEDBACK}

The triad, complexity, accuracy and fluency, referred to as CAF, has been used as "descriptors for the oral and written assessment of language learners as well as indicators of learners' proficiency underlying their performance," among other uses (Housen \& Kuiken 2009: 461). While complexity and fluency (conceptual fluency too) play a paramount role at university level, given the context in which the present study takes place, namely, EMI, we will focus on the component of accuracy, "the ability to produce-error free speech" (p. 461).

In the literature, the distinction between error/mistake is frequently made. While this distinction is a problematic one, we believe that James's (1998) definition can be useful bearing in mind the fact that our study is focused on students' written production. James defines error "as being an instance of language that is unintentionally deviant and is not self-corrigible by its author", whereas a mistake "is either intentionally or unintentionally deviant and self-corrigible" (p. 78). However, on many occasions it is a rather complex task to determine whether a mistake is a slip or a genuine error. In this paper, since we will be analysing students' essays, in which they have the opportunity to reread the text and make the necessary corrections, we believe that the use of the term error is more.

An additional distinction worth considering is that between direct or explicit feedback as opposed to indirect or implicit feedback. Explicit feedback is characterized by the provision of the correct linguistic form or structure, such as crossing out an unnecessary word or morpheme, or the insertion of a missing word or morpheme. Implicit feedback consists in indicating that an error has been made but without any explicit correction; for example, by circling the error, or by using a code to show what type of error it is (Bitchener \& Knoch, 2009). Elola and Oskoz (2016) point out that research on the preference of one type over the other is not conclusive. These authors claim that implicit feedback fosters students' problem-solving abilities and reflection on language, but it can also turn out to be confusing if the error correction codes are unfamiliar or abstruse, especially if the errors under scrutiny are complex. Accordingly, Elola and Oskoz (2016) conclude that direct and indirect feedback may yield complementary results, although we need to remember that the complex nature of learner engagement with written corrective feedback is well documented and there are therefore no simple recipes (Han \& Hyland, 2015).

Although error correction has generated much controversy in second language teaching (Lasagabaster \& Sierra, 2005; Ellis, 2009) due to the fact that the corrective feedback "research literature is so broad and ranging that it is inadvisable to make generalizations about the benefits of any particular type of corrective feedback" (Lyster \& Ranta, 2013:181), there is widespread agreement on the importance of teachers' feedback when it comes to fostering students' language development. In his meta-analysis of 33 studies, Li (2010) found that there was a positive effect of corrective feedback and that the effect was maintained over time. This author also concluded that implicit feedback was more effective than explicit feedback and that studies undertaken in foreign language contexts produced larger effect sizes than those in second language contexts. 
Since our study is undertaken in a foreign language context, the latter conclusion is of particular interest.

In the same vein, Ellis (2009) highlights that, although different opinions are found in the debate about the most effective strategies for correcting learners' errors in written compositions, some recent studies have demonstrated that written corrective feedback can lead to acquisition. However, he concludes that "contextual factors influence the extent to which corrective feedback is effective" (p. 5). Overall, practitioners support selective oral corrective feedback, whereas with written work they tend to correct the majority (if not all) errors (Milla, 2017). However, research studies on written corrective feedback are not so conclusive about the need to carry out such extensive correction and favour a more focused type of feedback (Ellis, Sheen, Murakami \& Takashima, 2008).

As for students, Lasagabaster and Sierra (2005) found out that students demand feedback which is informative, positive and non-judgemental, because otherwise it may become detrimental to students' self-efficacy beliefs (Mills, Pajares \& Herron, 2007). Han and Hyland (2015) also render important to listen to students' beliefs and affirm that students need to view feedback as a language learning opportunity if they are to be engaged in the feedback process, an opinion also shared by Amrhein and Nassaji (2010) after comparing teachers' and students' beliefs and attitudes towards written corrective feedback.

Busse (2013) found out that first year university students learning German as L2 displayed an increasing sense of insecurity and less willingness to put effort into writing when feedback was absent. Interestingly, feedback was perceived as demotivating when it was comprehensive rather than selective, when students were unfamiliar with the marking system, and when feedback was not specific enough to be helpful. Her results suggest that "feedback is highly important to students, in particular to students with low self-efficacy beliefs" (p. 419).

To wrap up with this section, we would like to underscore that the vast majority of research on writing in second languages has been undertaken in English-speaking contexts (Manchón, 2009), which is why some authors question whether the pedagogies that emanate from them are appropriate in foreign language contexts (Cumming and others, 2018). The latter caveat can also be extended to EMI non-English-speaking settings in which English is a foreign language, as is the case of the present study.

\section{Corrective FeEdback in EMI Settings}

EMI students find writing long pieces of texts challenging (Hernández-Nanclares \& Jiménez-Muñoz, 2017). Research indicates that, if linguistic gains are to be attained, some focus on form and language guidance on the part of the EMI lecturer is needed. For error correction to be efficient, the learner needs to be aware of being corrected and must understand the nature of the correction (Roberts, 1995). The challenge for teachers is therefore to provide students with corrections that their students both notice and understand. When 
dealing with errors, feedback becomes a key term, as it is a key aspect of foreign language learning. Since feedback is a dialogic process in which teachers help students to reach a higher level of competence as long as the latter are adequately scaffolded, EMI teachers should pay attention to the feedback they provide to their students.

As far as the writing skill is concerned, Han and Hyland (2015: 31) claim that "Providing feedback on linguistic errors in L2 learners' writing is one of the central concerns of L2 teachers", a concern that the studies reviewed above show, but which cannot be extrapolated to EMI lecturers. The fact that all teachers are language teachers is a dictum among language teachers (for them language correction is a responsibility of all the faculty members and not only of language specialists), but this is far from being the case among EMI content teachers.

There is very little research on how university lecturers deal with corrective feedback in EMI classes and, to our knowledge, no previous study has compared language and content lecturers' corrections. According to Milla (2017), the number of studies on this topic at pre-university level is also scant, as she could only find, apart from her own $\mathrm{PhD}$ dissertation, two additional studies (Llinares \& Lyster, 2014; Milla \& García Mayo, 2014) focused on CLIL (content and language integrated learning) in her review of the literature. At this stage it needs to be mentioned that, at pre-university level, the label CLIL is much more widespread than EMI for two main reasons. Firstly, because at pre-university level teachers pay more heed to language than their tertiary level counterparts. Secondly, because the presence of foreign languages other than English is more commonplace in primary and secondary education than in higher education institutions, where English clearly holds the upper hand (Dimova, Hultgren \& Jensen, 2015; Linn, 2016). Although the acronym CLIL does not explicitly refer to English (unlike EMI), it is also the dominating foreign language in primary and secondary education.

In the first of the two aforementioned studies, Llinares and Lyster (2014) compared immersion and CLIL contexts in primary education. An interesting finding of this research is that the corrected feedback patterns were similar in immersion and CLIL classrooms. However, the CLIL teachers were more conscious of the language aspect, which Llinares and Lyster attributed to three factors: (i) the CLIL teachers were also EFL (English as a foreign language) teachers, (ii) they were non-native speakers of English, and (iii) the integration of language and content in primary education CLIL is generally more common than in immersion programmes. These authors also concluded that it is important to consider teachers' beliefs about the most effective type of feedback, as they shape their corrective feedback movements.

In the second study, Milla and García Mayo's (2014) sample was made up of 17-18 year olds, that is, students who were enrolled in the last year of pre-university education and therefore just a year younger than the undergraduates participating in our study. They observed that CLIL lessons were more focused on content, whereas EFL lessons were more formoriented, as reflected by the percentage of errors corrected in the students' oral productions: $53 \%$ versus $72 \%$. Moreover, whereas the CLIL teacher nearly exclusively provided implicit feedback, the EFL teacher offered more explicit feedback and, more importantly, a wider range of corrective feedback movements. 
The third study is Milla's (2017) PhD dissertation, in which she analysed an EFL teacher's and a CLIL teacher's beliefs on error correction of 17-18 year-old students' oral productions. Although both teachers shared very similar beliefs about the positive effects of corrective feedback, through classroom observation Milla detected that the EFL teacher corrected almost $80 \%$ of all errors, whereas this percentage plummeted to $20 \%$ in the case of the CLIL teacher. Once again, significant differences were found depending on the learning context under analysis, that is, whether it was an EFL or a CLIL context.

Last but not least, it has to be underscored that the three studies reviewed above were focused on oral corrective feedback alone. Therefore more research on written corrective feedback is needed in general and in EMI university contexts in particular.

\section{The STUdY}

\subsection{Research questions}

Bearing in mind all the issues raised above, the research questions (RQ) that drove this study were the following:

RQ1: What is the content and language teacher's position regarding the errors in written work in the foreign language? That is to say, are language-related errors similarly identified by the language and the content teachers?

RQ2: What are the main type of errors that EMI students make in their written work?

RQ3: Is there a correlation between the quality of the written composition (i.e. the number of language errors) and the mark given by the content teacher?

\subsection{The context}

In this paper we analysed data from the University of the Basque Country (UBC) in the Autonomous Community of the Basque Country (north of Spain). The UBC is an officially Spanish/Basque bilingual public university and its EMI programmes are part of the Multilingualism Program (MP) whereby courses are taught in French, and English (95\% of the courses in the MP are offered in the latter). The MP, which was launched in $2005 / 2006$, aims to facilitate student mobility and employability, attract international students and researchers and foster the international profile of the university. Any student can enroll in EMI programmes since no proof of English proficiency is required. The teaching staff, however, need to show proof of a $\mathrm{C} 1$ proficiency level of the Common European Framework of Reference for Languages in order to participate in them. In the academic year 2016/17 the EMI programmes had around 4,798 students and 1,080 qualified teaching staff to teach on the programme. 


\subsection{Description of the tasks and the participants}

In this study, we wanted to analyse the written production of students on EMI courses. In particular, we wanted to compare the content teacher's markings of the students' papers with our markings as language teachers. In order to do so, we asked the lecturer of the "World economic history" course to provide us with some of his students' essays. The essays were take-home assignments and counted $20 \%$ of the total grade of the course.

In the year 2016/17 when the essays were collected, the course "World economic history" had 23 students, 11 of whom were History students and 12 Business Administration and Management (BAM) students. The former had enrolled in the course voluntarily as they did not have to meet any English language requirements to graduate, but the latter had done so as part of the school's requirement to prove their proficiency in English in order to earn their degree. The other two ways to meet the requirement were writing their end of studies project in English or providing an English proficiency certificate at B2 level.

Altogether we analysed 20 essays written as part of two assignments: 16 essays, - the total number of the essays which were handed in by the students for the first assignment, and 4 for the second. The first assignment consisted of a commentary on a set number of pages from Adam Smith's Wealth of Nations; the second task was also a commentary on the existence of a Malthusian Crisis in China based on data provided by the instructor. The essays were 4 or 5 pages long and had to be written on both sides of the paper. The lecturer asked the students to write the essays by hand rather than on their computers to avoid plagiarism and to make the task more challenging for the students. However, 5 out of the 20 essays were typed and 5 contained plagiarised sections. Table 1 contains the information on the individual essays and their authors. The mark provided by the content teacher is also given (the essays were worth a maximum of 2 points each). 
Table 1. The essays, their authors and the marks given

\begin{tabular}{|c|c|c|c|c|c|}
\hline Essay & Student & & Assignment 1 & Mark & Assignment 2 \\
\hline 1 & 1 & History & $\mathrm{X}$ & 2 & \\
\hline 2 & 2 & History & $\mathrm{X}$ & 1 & \\
\hline 3 & 3 & History & $\mathrm{X}$ & 0.75 & \\
\hline 4 & 4 & History & $\mathrm{X}$ & 0.75 & \\
\hline 5 & 5 & History & $\mathrm{X}$ plagiarised & 0.50 & \\
\hline 6 & 6 & Erasmus & $\mathrm{X}$ & 0.50 & \\
\hline 7 & 7 & History & $X$ & 0.50 & \\
\hline 8 & 8 & History & $\mathrm{X}$ & 1.2 & \\
\hline 9 & 9 & History & $\mathrm{X}$ & 1 & \\
\hline 10 & 10 & BAM & $\mathrm{X}$ plagiarised & 0.50 & \\
\hline 11 & 11 & BAM & X typed & 0.75 & \\
\hline 12 & 12 & BAM & $\mathrm{X}$ & 0.75 & \\
\hline 13 & 13 & BAM & X typed & 0.75 & \\
\hline 14 & 14 & BAM & $\mathrm{X}$ plagiarised & 0.50 & \\
\hline 15 & 15 & BAM & $\mathrm{X}$ plagiarised & 0.50 & \\
\hline 16 & 16 & BAM & $\mathrm{X}$ & 0.50 & \\
\hline 17 & 10 & BAM & & 1 & $\mathrm{X}$ \\
\hline 18 & 12 & BAM & & 0.75 & X typed \\
\hline 19 & 11 & BAM & & 0.75 & X typed \\
\hline 20 & 13 & BAM & & 0.75 & $\begin{array}{l}\text { X typed \& } \\
\text { plagiarised }\end{array}$ \\
\hline
\end{tabular}




\subsection{Procedure}

Once the essays were collected, in order to ensure that the two language teachers (the two authors of this paper) used the same guidelines in the evaluation of the essays, we picked two essays from the pool of papers arbitrarily and marked the errors individually. We compared the errors that had been identified, and reached an agreement on the categories into which the errors were to be classified. The six categories for the categorisation of the errors were: coherence/cohesion, grammar, punctuation, register, spelling and vocabulary. In addition, consensus was reached on a number of marking issues. However, some subjectivity and therefore some differences in the count of the errors by the two researchers were unavoidable, as for example in the case of it is know (essay 20) which could be considered a spelling or a grammar error. Once the marking guidelines were agreed on, we marked the papers individually and compared the errors that we had identified with the errors identified by the content teacher.

\section{RESUlts}

The first research question addressed the content and the language teachers' position towards the language-related errors in the students' essays. A descriptive analysis of the errors revealed that the language teachers did a thorough job in the marking of the errors, while the content teacher did not mark the errors systematically or consistently. Failure to identify all the errors by the latter was most evident in the case of poorly written essays although he usually wrote a comment which appeared to be addressed to him rather than the student at the end of the essay (e.g. "Badly written. Full of mistakes. It's nearly impossible to understand what he tries to say." essay 16).

The content teachers used various markings such as underlines, exclamation marks, interrogation signs, circles around words, all of which were used to single out both content and language errors alike. In particular, he used (single, double or even triple) underlines to point to sentences and whole paragraphs that were difficult to understand, to single out inconsistencies and inaccurate statements or facts, and when a conclusion did not follow from its argument, for example. He tended to restrict double exclamation marks (!!) or a vertical line parallel to the fragment of the text to state that he did not agree with the statement that had been put forward in that paragraph, and interrogation marks $(i$ ?) when a sentence was hard to understand. He also made some notes in the margins when the comment had to do with the content (e.g. "Previously he has stated the opposite. This is a contradiction", essay 2 ). In addition, he did not usually mark punctuation or spelling errors, even when they were recurrent (e.g. "consecuence") and did not tend to provide any corrective feedback, not even in the case of very basic grammar mistakes (e.g. the omission of the subject or 3rd person $-\mathrm{s}$ ). He made a few corrections here and there of errors that could easily be corrected (e.g. the inclusion of the pronoun 'it' in the sentence: "and exchange [it] to gain all...", essay 13). He only provided corrective feedback in the case of errors in specialized vocabulary, which were scarce. The language teachers, on the other hand, underlined each individual error and identified the category the error belonged to (vocabulary, grammar, spelling, etc.). 
In order to address the first research question from a quantitative perspective we compared the number of errors identified by the content teacher and the two language teachers. As Table 2 shows, the difference in the mean of the number of errors per essay noted by the content teacher (17.85 errors per essay) on the one hand, and by the language teachers (91.25/93.55, respectively) on the other hand, is noteworthy.

Table 2. Number of errors identified by each of the three evaluators

\begin{tabular}{|c|c|c|c|}
\hline Essay & Content Teacher & Language Teacher 1 & Language Teacher 2 \\
\hline 1 & 14 & 100 & 96 \\
\hline 2 & 21 & 62 & 63 \\
\hline 3 & 35 & 126 & 125 \\
\hline 4 & 12 & 47 & 50 \\
\hline 5 & 21 & 104 & 101 \\
\hline 6 & 18 & 190 & 178 \\
\hline 7 & 10 & 39 & 35 \\
\hline 8 & 36 & 164 & 170 \\
\hline 9 & 18 & 98 & 106 \\
\hline 10 & 10 & 47 & 59 \\
\hline 11 & 30 & 172 & 191 \\
\hline 12 & 2 & 26 & 27 \\
\hline 13 & 8 & 20 & 24 \\
\hline 14 & 13 & 105 & 118 \\
\hline 15 & 15 & 97 & 102 \\
\hline 16 & 41 & 219 & 214 \\
\hline 17 & 20 & 48 & 46 \\
\hline 18 & 10 & 33 & 31 \\
\hline 19 & 19 & 106 & 112 \\
\hline 20 & 4 & 22 & 23 \\
\hline Total & 357 & 1825 & 1871 \\
\hline Mean & $\begin{array}{c}17.85 \\
(\mathrm{SD}=10.60)\end{array}$ & $\begin{array}{c}91.25 \\
(\mathrm{SD}=59.25)\end{array}$ & $\begin{array}{c}93.55 \\
(\mathrm{SD}=59.41)\end{array}$ \\
\hline
\end{tabular}


Since the data was normally distributed, parametric tests were carried out. Statistically significant differences were found when the content teacher's evaluation was compared with that of both language teacher $1[\mathrm{t}(19)=6.44, \mathrm{p}<0.001]$ and language teacher $2[\mathrm{t}(19)=6.62, \mathrm{p}<0.001]$. This difference represented a large effect-size in both cases: eta squared $=0.52$ in the first case and eta squared $=0.53$ in the second. Therefore, the data reveals that the language teachers detected a considerably higher number of errors than the content teacher and the magnitude of these differences was very large. Conversely, the paired-samples t-tests indicated that there were no significant differences when the number of errors found by language teacher 1 and language teacher 2 were compared $[\mathrm{t}(19)=-1.43, \mathrm{p}=0.168]$. In short, the position of the language teachers and the content teacher with respect to the marking of errors in written compositions in the foreign language, English, differed quite clearly: the two language teachers took a much more thorough approach than the content teacher.

The next research question sought to identify the kind of errors that EMI students made in their essays. Since the content teacher did not mark all the errors as illustrated by the data in table 2, we considered the errors and the error types marked by the language teachers. As stated above, the first thing that stands out is the daunting mean number of errors made by the students per essay $(M=92.4)$, especially given the fact that the students could revise their work at home and refer to grammar books and dictionaries to avoid grammar, spelling and vocabulary errors. Next, we ranked the means of the errors of the written texts in the categories of grammar, spelling, punctuation, vocabulary, coherence and register. Figure 1 provides the means for each category.

Figure 1. Mean of students' errors by category

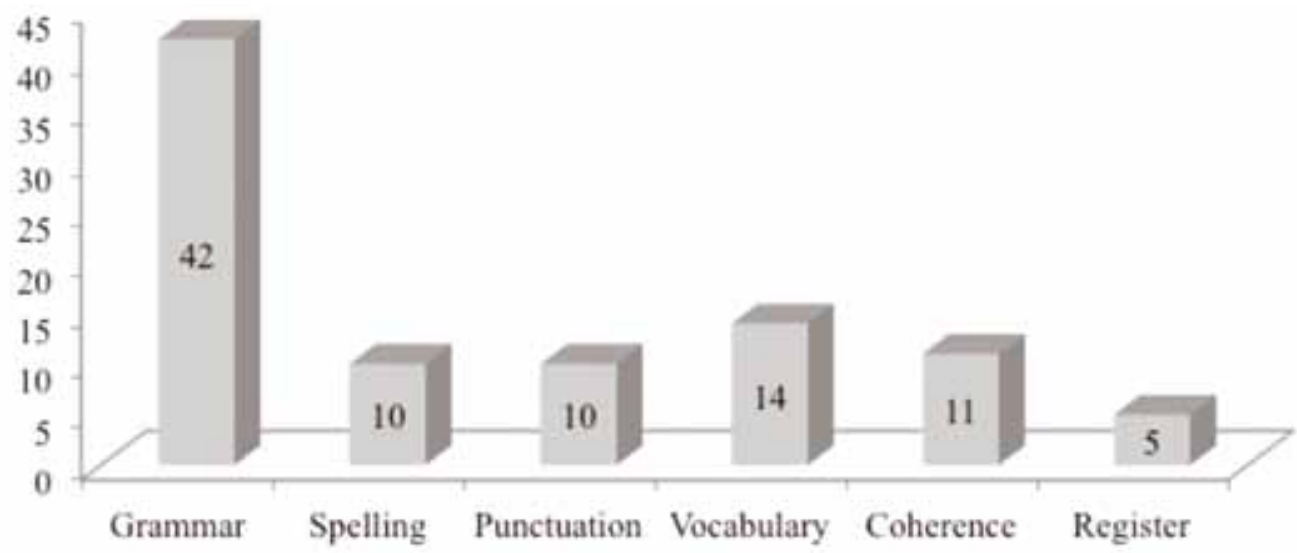

The grammar errors clearly stand out as the most common (42 errors), while register errors are the least frequent (5). The grammar errors mainly consisted of the omission of the $-s$ for the $3^{\text {rd }}$ person morpheme; the omission of the subject, the ungrammatical use of articles and word order, and the ungrammatical choice of prepositions. The vocabulary errors (14) included the use of false friends and incorrect collocations, problems with non-specialised vocabulary in most cases and only in a few cases with specialissummarizeded or technical 
words. Spelling errors revealed the interference of the students' L1 (e.g. the Basque influence in the spelling of "impact" with an " $n$ " instead of an " $m$ ") and included misspellings. Punctuation errors (10) consisted of inappropriate command semi-colon use and a lack of full stops. Under the category of coherence and cohesion (11 errors), we included incomplete sentences, sequence of ideas which were not logically ordered, sentences which were not constructed or connected well, the occurrence of demonstratives and pronouns whose referents were unclear and the use of the wrong linking word or incorrect linking words (e.g. "in one hand"). Finally, the errors in register consisted of the use of subject/auxiliary contractions (e.g. "it's", "don't") and inappropriate choice of words (e.g. "the author says" rather than "states", "claims" or "argues") primarily.

Next, the comparison of the means of the number of errors found in each essay per category summarised in Table 3 shows that there is a high degree of variability among the essays; for instance, while there were a total of 216.5 errors in essay 16, there were 22 in essay 13. The means are obtained from both language teachers' corrections, which is why some means are X.5 (e.g. essay 1 Register $=1.5$ ).

Table 3. Mean number of errors per category in each essay identified by the language teachers

\begin{tabular}{|c|c|c|c|c|c|c|c|}
\hline Essay & Grammar & Spelling & Punct. & Vocab. & Coher. & Regist. & Total \\
\hline $\mathbf{1}$ & 40 & 8.5 & 12 & 20 & 15 & 2.5 & 98 \\
\hline $\mathbf{2}$ & 29 & 4.5 & $\mathbf{2}$ & 18 & 9 & $\mathbf{0}$ & 62.5 \\
\hline $\mathbf{3}$ & 65 & 14 & 16 & 18.5 & 12 & $\mathbf{0}$ & 125.5 \\
\hline $\mathbf{4}$ & 18 & 11.5 & 7 & 5 & 6.5 & 0.5 & 48.5 \\
\hline $\mathbf{5}$ & 40 & 12 & 6.5 & 23.5 & 10.5 & 10 & 102.5 \\
\hline $\mathbf{6}$ & 100 & $\mathbf{2 9 . 5}$ & 10.5 & 26.5 & 15 & 2.5 & 184 \\
\hline $\mathbf{7}$ & 14 & 5.5 & 5.5 & 6.5 & 4 & 1.5 & 37 \\
\hline $\mathbf{8}$ & 81 & 36 & 10 & 20 & 16 & 4 & 167 \\
\hline $\mathbf{9}$ & 45 & 8.5 & 16 & 11 & 6.5 & 15 & 102 \\
\hline $\mathbf{1 0}$ & 17 & 5.5 & 11.5 & 1.5 & 7 & 10.5 & 53 \\
\hline $\mathbf{1 1}$ & 75.5 & 13.5 & $\mathbf{1 9 . 5}$ & $\mathbf{3 5}$ & 22.5 & $\mathbf{1 5 . 5}$ & 181.5 \\
\hline $\mathbf{1 2}$ & $\mathbf{4}$ & 2.5 & 13 & 5 & $\mathbf{1}$ & 1 & 26.5 \\
\hline $\mathbf{1 3}$ & 9 & $\mathbf{1}$ & 3.5 & 2.5 & 5.5 & 0.5 & $\mathbf{2 2}$ \\
\hline $\mathbf{1 4}$ & 47 & 19.5 & $\mathbf{1 9 . 5}$ & 15.5 & 8 & 2 & 111.5 \\
\hline $\mathbf{1 5}$ & 50 & 3 & 14.5 & 16 & 8 & 8 & 99.5 \\
\hline $\mathbf{1 6}$ & $\mathbf{1 1 2 . 5}$ & 15.5 & 4 & 35 & $\mathbf{4 5}$ & 4.5 & $\mathbf{2 1 6 . 5}$ \\
\hline $\mathbf{1 7}$ & 21.5 & 1.5 & 5.5 & 6.5 & 4 & 8 & 47 \\
\hline $\mathbf{1 8}$ & 15 & 3 & 5 & 2.5 & 6 & 0.5 & 32 \\
\hline $\mathbf{1 9}$ & 50.5 & 10.5 & 14 & 12.5 & 14 & 7.5 & 109 \\
\hline $\mathbf{2 0}$ & 7 & 4.5 & 4 & $\mathbf{1 . 5}$ & 3.5 & 2 & 22.5 \\
\hline $\mathbf{T o t a l}$ & 841 & 210 & 199.5 & 282.5 & 219 & 96 & \\
\hline & & & & & & & \\
\hline
\end{tabular}


In addition, table 3 reveals that the range in the number of errors varies widely from one category to another. For example, the largest difference was found in the case of the grammar errors, which ranged from 112.5 (essay 16) to just 4 (essay 12) and the smallest in the category of register from 15.5 to 0 (essays 11 and 2, respectively). The ranges of errors for the other categories are coherence 45 vs. 1, vocabulary 35 vs. 1.5 , spelling 29.5 vs. 1 , and punctuation 19.5 vs. 2 .

Our next objective focused on the analysis of the strength of the correlation between the errors committed by the students and the content scores. In addition, we also wanted to determine whether there is a correlation between the different language measures and the score provided by the content teacher. The results provided in the first column of table 4 revealed that there is no correlation between the number of errors and the content score. As for the second goal, the results in table 4 showed that none of the language components correlated with the content score. In other words, none of the six language features considered, including the grammar errors which were the most frequent ones by far, seemed to influence the content teacher's evaluation of the essays.

Table 4. Correlations between the language measures and the content score

\begin{tabular}{|c|c|c|c|c|c|c|c|c|}
\cline { 2 - 9 } \multicolumn{2}{|c}{} & $\begin{array}{c}\text { Total } \\
\text { number } \\
\text { of errors }\end{array}$ & Grammar & Spelling & Punct. & Vocab. & Coher. & Regist. \\
\hline \multirow{3}{*}{ Score } & $\begin{array}{c}\text { Pearson's } \\
\text { correlation }\end{array}$ & -0.038 & -0.068 & 0.008 & 0.011 & 0.026 & -0.019 & -0.074 \\
\cline { 2 - 9 } & $\begin{array}{c}\text { Sig. } \\
\text { (bilateral) }\end{array}$ & 0.873 & 0.777 & 0.974 & 0.964 & 0.912 & 0.937 & 0.757 \\
\cline { 2 - 9 } & $\mathrm{N}$ & 20 & 20 & 20 & 20 & 20 & 20 & 20 \\
\hline
\end{tabular}

Hence, even in the case of very poorly written essays, the content teacher did not take language into account, which clearly reflects the content teacher's disregard of language issues in EMI. For him language matters should not interfere with the students' end of course performance.

\section{Conclusions}

Different authors, such as Lasagabaster (2018) and Macaro (2018), underscore that a potential model for English language development in EMI courses should be based on the collaboration between content teachers and English language specialists. With this in mind, in this paper we sought out to analyse the content teacher's and the language teacher's position in relation to language errors in the students' writing in EMI, to characterize the quantity and type of errors students made in their written assignments, and to determine whether there was a correlation between students' writing skill and the score assigned by the content 
teachers. The main findings of the study and their teaching implications are provided next.

We have seen that the content lecturer identified a considerably smaller number of errors than the language lecturers. This result tallied with those obtained by Milla and García Mayo's (2014) and Milla's (2017) research at pre-university level and support the fact that the teachers' profiles have a great impact on corrective feedback (Milla, 2017; Milla \& García Mayo, 2014). Moreover, we observed that the content lecturer's range of errors was much more limited and many of the errors were underlined together if they happened to be in the same sentence. By contrast, the language lecturers had a clear tendency to highlight errors individually and to classify the kind of error in one of the six categories which had been posited. Hence, the results reveal that there is clearly a mismatch between the content teacher's and the language teacher's corrections.

The differences in the way that the content teacher and the language teacher tackle student errors reveal the need to make a decision regarding the best alternative for the students' needs. Obviously, when it comes to error correction, the pendulum should not go full swing and EMI teachers should endeavour to prevent those conflicts that may augment frustration, anxiety and lack of motivation on the part of the student, or even their giving up EMI courses due to the frustration caused by strict linguistic corrections. Lasagabaster and Sierra (2005) underscore that students state their preference for not being corrected constantly, as they feel inhibited, although this does not mean that they do not wish to be corrected. In addition, we observed that a significant percentage of oral error-correction movements went unnoticed by students, as fewer than a third were actually realized. This lack of error awareness is closely linked to the corrections made by the content teacher, whose underlining of whole sentences whenever a few grammar mistakes were found in the same clause is possibly of little help to students. However, it also needs to be noted that Mantello's study (1997) confirmed that students who had experienced the correction of a written exercise were in favour of being less corrected and preferred their teacher to devote more time to a smaller number of errors. Consequently, an intermediate position would more than likely be the right option as there is a need to try to find some balance. In short, language and content lecturers need to reflect on their written corrective feedback practices since the former's scant and erratic corrections may not be of much help, and the latter's excessive number of corrections may only lead to students' frustration and demotivation.

The second conclusion of the paper is the daunting number of errors made by the students. On the face of this fact, it seems legitimate to question the suitability of the participation in EMI programs of students whose level of English is low. Perhaps stakeholders should consider limiting access to the programs in these cases. As for the type of errors made by the students, grammar errors stood out from the other categories significantly (i.e. vocabulary errors, coherence, spelling/punctuation and register). However, while grammar, spelling and vocabulary errors result from the students' low competence in English and denote underlying specific language problems, coherence and register errors suggest the existence of a more fundamental problem with the students' writing skills which probably also affects the L1. The identification of the source of the errors is crucial if we want to reduce their number.

The poor quality of many of the essays seem to support Costa's (2012) claim that EMI lecturers need to be taught how to tackle language objectives in their content courses, corrective feedback being an important part of lecturers' reflective process. However, Costa also acknowledges that it is very complex for higher education institutions to impose a traditional 
training course, which is why "perhaps training should be rethought of as an exercise in self-awareness, self-discovery, and personal internationalization" (p. 43). Our study points in this direction, as we believe it may help EMI lecturers to come closer to self-awareness, self-discovery and personal internationalization; but this process is more likely to succeed if content lecturers can rely on the support of language specialists.

With this in mind, the following procedure could be a possible way out. Firstly, researchers/language teachers would need to address how to provide an effective language support framework from which both teachers and students can benefit (Symon \& Weinberg, 2015). Secondly -and closely linked - we strongly believe that by exploring students' opinions we can obtain information essential for improving the learning process in general and error correction strategies in particular in EMI contexts. In fact, a first contact with a small group of World economic history students in a focus group revealed that they believe that the content teacher should not spend a lot of time discussing language issues and that content is more important than form. By listening to their students, EMI lecturers will be more likely to sustain students' commitment and protect their enthusiasm (Busse, 2013; Garrett \& Shortall, 2002). Bearing in mind that there are no "simplistic pedagogical proscriptions and prescriptions" about how to implement corrective feedback (Ellis, 2009:15) and that "it may not be necessary or even possible for researchers to identify the single most effective CF strategy" (Lyster, Saito \& Sato, 2013: 21), a possible course of action could be to negotiate with students what type of errors should be corrected, and decide on what type of feedback may be more useful taking into account their opinions. In fact, Amrhein and Nassaji (2010) claim that teachers need to openly discuss the use of written corrective feedback with their students and to foster their positive attitudes towards corrective feedback, as this will positively affect their noticing of teachers' corrections (Kartchava \& Ammar, 2014).

Since a selection of errors to target is more viable in the written than in the oral mode, another option would be for language teachers to select the most communicatively disturbing errors and, after reaching a consensus with both content lecturers and students, to establish a clear-cut corrective feedback classroom policy. This would be in line with methodologists who state that it is better to correct a few error types rather than attempt to address all of them (Ellis, 2009). Our study was carried out in the first year of the degree, which is why the feedback policy can be widened in subsequent years, so that students are able to correct all or, more realistically, at least the majority of their errors by the end of the degree in the fourth year. What seems clear to us is that the correction of errors carried out by the content teacher in this study is likely to yield poor results, as EMI students need more focused indications (Ellis, Sheen, Murakami \& Takashima, 2008) to profit from written corrective feedback. Action research projects based on team teaching (in which language and content teachers collaborate) can help to overcome these linguistic hurdles and improve not only students' English competence, but also their content learning and provide content teachers the training to conduct error correction.

The third conclusion has to do with the possible existence of a correlation between the number or type of language errors and the mark given by the content teacher. It has sometimes been stated in the literature that language affects students' final grade as a good composition is more likely to be highly marked than one teeming with grammar mistakes. However, the studies for the Swedish context (Airey, 2009), Italy (Costa, 2012) and Catalonia in Spain (Aguilar, 2017) have shown that this seems not to be the case in EMI settings, 
where lecturers do not concern themselves with language issues. Our data have shown that there is no correlation between the quality of the composition and the score given by the content teacher. In other words, we were able to conclude that the EMI content teacher does not consider language when marking his students' essays. The lack of any significant correlation could be accounted for by the fact that content teachers do not perceive themselves as language teachers.

As for limitations, the main shortcoming of this study is the small number of essays considered. For future research, the pool of essays and teachers' corrections should be bigger. In addition, we tackled one small aspect dealing with language in EMI, but there are many other related issues that could be researched in the future. For example, it would be very interesting to compare students' written work in the L1 and in the foreign language for the same subject on EMI courses and on regular courses. Comparing how students write for similar assignments would allow us to see whether certain errors, such as errors in coherence/cohesion, may be attributed to faulty knowledge of the foreign language or a more fundamental lack of writing competence. Knowing where and how the errors in L1 and L2 originate is crucial to their remedy.

\section{REFERENCES}

Aguilar, M. (2017). Engineering lecturers' views on CLIL and EMI. International Journal of Bilingual Education and Bilingualism, 20, 722-735.

Airey, J. (2012). 'I don't teach language.' The linguistic attitudes of physics lecturers in Sweden. AILA Review, 25, 64-79.

Amrhein, H. R. \& Nassaji, H. (2010). Written corrective feedback: What do students and teachers prefer and why? Canadian Journal of Applied Linguistics, 13, 95-127.

Bitchener, J. \& Knoch, U. (2009). The relative effectiveness of different types of direct written corrective feedback. System, 37, 322-329.

Busse, V. (2013). How do students of German perceive feedback practices at university? A motivational exploration. Journal of Second Language Writing, 22, 406-424.

Costa, F. (2012). Focus on form in ICLHE lectures in Italy: Evidence from English-medium science lectures by native speakers of Italian. AILA Review, 25, 30-47.

Costa, F. \& Mariotti, C. (2017) Differences in content presentation and learning outcomes in English-medium instruction (EMI) vs. Italian-medium instruction (IMI) contexts, in J. Valcke \& R. Wilkinson (Eds.), Integrating content and language in higher education: Perspectives and professional practice (pp. 187-204). Frankfurt am main: Peter Lang.

Cumming, A. and others (2018). Students' practices and abilities for writing from sources in English at universities in China. Journal of Second Language Writing, 39, 1-15.

Dafouz, E. (2011). English as a medium of instruction in Spanish contexts, in Y. Ruiz de Zarobe, J. M. Sierra \& F. Gallardo (Eds.), Content and foreign language integrated learning (pp. 189-209). Bern: Peter Lang.

Dafouz, E., Camacho, M. \& Urquia, E. (2014). 'Surely they can't do as well': A comparison of business students' academic performance in English-medium and Spanish-as-first-language medium programmes. Language and Education, 28, 223-236.

Dimova, S., Hultgren, A. K. \& Jensen, C. (Eds.) (2015). English-medium instruction in European higher education. Boston/Berlin: De Gruyter Mouton. 
Ellis, R. (2009). Corrective feedback and teacher development. L2 Journal, 1, 3-18.

Ellis, R., Sheen, Y., Murakami, M., \& Takashima, H. (2008). The effects of focused and unfocused written corrective feedback in an English as a foreign language context. System, 36, 353-371.

Elola, I. \& Oskoz, A. (2016). Supporting second language writing using multimodal feedback, Foreign Language Annals, 49, 58-74.

Garrett, P. \& Shortall, T. (2002). Learners 'evaluations of teacher-fronted and student-centred classroom activities. Language Teaching Research, 6, 25-57.

Han, Y. \& Hyland, F. (2015). Exploring learner engagement with written corrective feedback in a Chinese tertiary EFL classroom. Journal of Second Language Writing, 30, 31-44.

Hernández-Nanclares, N. \& Jiménez-Muñoz, A. (2017). English as a medium of instruction: Evidence for language and content targets in bilingual education in economics. International Journal of Bilingual Education and Bilingualism, 20, 883-896.

Housen, A \& Kuinen, F. (2009). Complexity, accuracy, and fluency in second language acquisition. Applied Linguistics, 30, 461-473.

James, C. (1998). Errors in Language Learning and Use: Exploring Error Analysis. Harlow: Longman.

Kartchava, E. \& Ammar, A. (2014). Learners' beliefs as mediators of what is noticed and learned in the language classroom. TESOL Quarterly, 48, 86-109.

Lasagabaster, D. (2018). Fostering team teaching: Mapping out a research agenda for Englishmedium instruction at university level. Language Teaching, 51, 400-416.

Lasagabaster, D. (in press). The impact of the spread of English-medium instruction on Spanish universities. Language Teaching.

Lasagabaster, D. \& Sierra, J. M. (2005). Error correction: students' versus teachers' perceptions. Language Awareness, 14, 112-127.

Li, S. (2010). The effectiveness of corrective feedback in SLA: A meta-analysis. Language Learning, 60, 309-365.

Linn, A. (Ed.) (2016). Investigating English in Europe: Contexts and Agendas. Boston/Berlin: De Gruyter Mouton.

Llinares, A. \& Lyster, R. (2014). The influence of context on patterns of corrective feedback and learner uptake: A comparison of CLIL and immersion classrooms. The Language Learning Journal, 42, 181-194.

Lyster, R. (2007). Learning and teaching languages through content: A counterbalanced approach. Amsterdam/Philadelphia: John Benjamins.

Lyster, R. \& Ranta, L. (2013). Counterpoint piece: The case for variety in corrective feedback research. Studies in Second Language Acquisition, 35, 167-184.

Lyster, R., Saito, K. \& Sato, M. (2013). State-of-the-art article: oral corrective feedback in second language classrooms. Language Teaching, 46, 1-40.

Macaro, E. (2018). English Medium Instruction: Content and Language in policy and practice. Oxford: Oxford University Press.

Manchón, R. (Ed.) (2009). Writing in foreign language contexts: Learning, teaching and researching. Bristol, UK: Multilingual Matters.

Mantello, M. (1997). A touch of ... class! Canadian Modern Language Review, 54, 127-31.

Milla, R. (2017). Corrective feedback episodes in CLIL and EFL classrooms: Teachers' and learners' beliefs and classroom behavior (Unpublished $\mathrm{PhD}$ dissertation). University of the Basque Country UPV/EHU, Vitoria-Gasteiz, Spain.

Milla, R. \& García Mayo, M. P. (2014). Corrective feedback episodes in oral interaction: A comparison of a CLIL and an EFL classroom. International Journal of English Studies, 14, 1-20. 
Mills, N. A., Pajares, F. \& Herron, C. (2007). Self-efficacy of college intermediate French students: Relation to achievement and motivation. Language Learning, 57, 417-442.

Nikula, T., Dafouz, E., Moore, P. \& Smit, U. (2016). Conceptualising integration in CLIL and multilingual education. Bristol, UK: Multilingual Matters.

Roberts, M. A. (1995). Awareness and the efficacy of error correction, in R. Schmidt (Ed.) Attention and Awareness in Foreign Language Learning (pp. 163-82). Honolulu, Hawai'i: University of Hawai'i.

Symon, M. \& Weinberg, L. (2015). Introducing EMI instruction in an EFL context: Can the integration of content and language in higher education improve students' English proficiency?, in R. Wilkinson \& M. L. Walsh (Eds.), Integrating content and language in higher education: From Theory to Practice. Selected papers from the 2013 ICLHE Conference (pp. 309-322). Frankfurt am main: Peter Lang.

Valcke, J. \& Wilkinson, R. (Eds.) (2017). Integrating content and language in higher education: Perspectives and professional practice. Frankfurt am main: Peter Lang.

\section{Acnowledgements}

This article falls within the work carried out in the following research projects: FFI201679377-P (Spanish Ministry of Economy and Competitiveness; AEI/FEDER, EU) and IT904-16 (Department of Education, University and Research of the Basque Government). 